\title{
JEUGDHULP IN TIJDEN VAN CORONA
}

\section{ERVARINGEN TIJDENS DE EERSTE GOLF}

De coronacrisis zorgt voor een abrupte transitie naar jeugdhulp op afstand. Van professionals vergt deze nieuwe manier van werken veel extra inzet en flexibiliteit en vooral: creativiteit. Wat gaat er goed en wat niet? En zijn er zelfs voordelen die we willen behouden? We vroegen 48 professionals naar hun ervaringen tiidens 'de eerste golf'.

\section{JOYCE WEELAND EN FLOOR VAN ROOIJ}

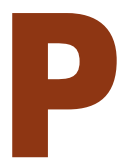
sychologen, (ortho)pedagogen en psychotherapeuten in het jeugddomein stonden in 2020 voor een grote uitdaging. De maatregelen die waren gericht op het voorkomen van verdere verspreiding van het coronavirus legden zware restricties op professionals en hun mogelijkheden tot 'live' contact met kinderen, jongeren, ouders en gezinnen. Veel jeugdhulp kon in deze periode slechts doorgaan op afstand, onder meer via beeldbellen. Een groot deel van de professionals had tot dan toe weinig of geen ervaring met de middelen die gebruikt worden voor hulpverlening op afstand. Niet per se omdat zij hier negatief tegenover staan, maar door hun algemene terughoudendheid in het vervangen van live contact door online contact, onzekerheid en gebrek aan training en ervaring (Aafjes-van Doorn e.a., 2020; Connolly e.a., 2020). Ondanks de vervelende aanleiding vormt de gedwongen en abrupte transitie van live naar online contact met kinderen, ouders en gezinnen een mooie proeftuin voor verdere verkenning van de geschiktheid en effectiviteit van online jeugdhulp.

Internationaal onderzoek tijdens de eerste golf van coronabesmettingen laat zien dat professionals kansen zien in het online werken, niet alleen voor het continueren van lopende hulp aan en de therapeutische relatie met cliënten, maar ook kansen om de drempel te verlagen voor gezinnen om hulp te zoeken en ontvan- gen (MacEvilly \& Brosnan, 2020; Racine e.a., 2020; Schieltz \& Wacker, 2020). Amerikaanse en Europese psychotherapeuten benoemen daarnaast als eerste indruk dat cliënten over het algemeen een positieve ervaring hebben met het online contact (Békés \& Aafjes-van Doorn, 2020). Professionals uiten echter ook zorgen, bijvoorbeeld over de beperkingen van

\section{CLIËNTEN ERVAREN ONLINE AFSPRAKEN ALS VRIJBLIJVENDER}

online werken voor interactieve methodieken en informeel sociaal contact voor, na of tijdens sessies; toenemende ongelijkheid, omdat niet alle cliënten beschikken over en ervaring hebben met de benodigde hard- en software, en hun eigen gebrek aan expertise in online werken (MacEvilly \& Brosnan, 2020; Racine e.a., 2020; Schieltz \& Wacker, 2020).

Ons onderzoek richt zich op de ervaringen van Nederlandse jeugdhulpprofessionals met hulp op afstand tijdens de pandemie. Welke factoren hebben volgens hen bijgedragen aan succesvolle hulp en wat zijn de ervaren barrières? En belangrijker nog: wat 


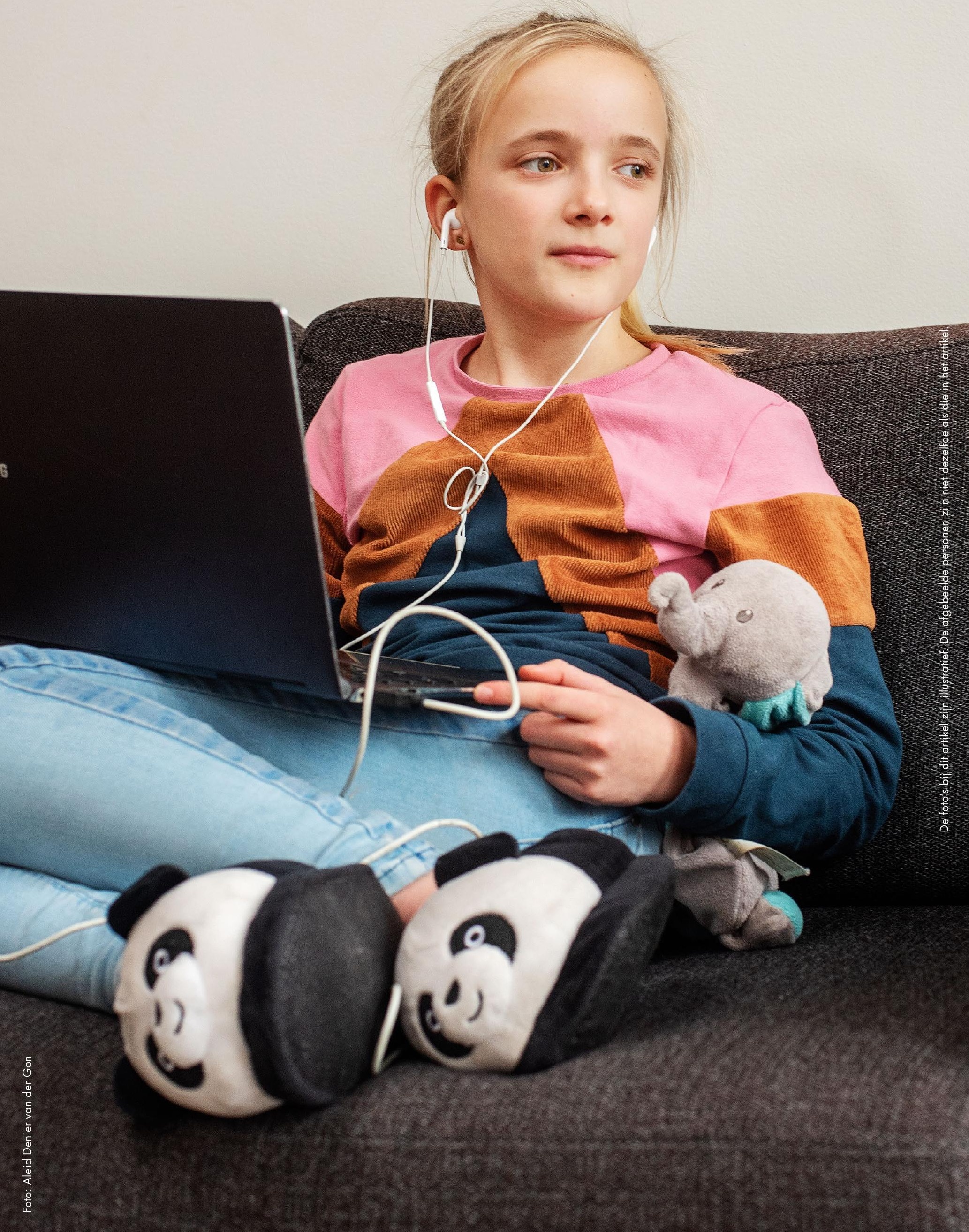


willen zij uit deze periode behouden als er straks weer meer mogelijk is en wat is volgens hen nodig wanneer nieuwe maatregelen live contact opnieuw belemmeren? In de periode van maart tot mei 2020 hebben wij 48 professionals (met minimaal hbo-opleidingsniveau) bevraagd aan de hand van een korte vragenlijst $(n=$ 27) die zij direct na een hulp-op-afstandsessie met ouders en/of kind invulden, een telefonisch interview $(n$ $=6$ ), of beide $(n=14)$ (zie tabel 1$)$. Het ging om vijf thema's: middelen en vaardigheden, privacy, contactname, inhoud en vorm, en effectiviteit van hulp op afstand. Deelnemers zijn, na goedkeuring door de ethiekcommissie van het Department of Psychology, Education, and Child Studies, Erasmus Universiteit Rotterdam (aanvraag 20-037), geworven via sociale media en nieuwsbrieven van opleidings- en beroepsorganisaties.

\section{BELLEN VANUIT DE AUTO}

De meeste deelnemende professionals gaven in de vragenlijst aan dat zij, voorafgaand aan de pandemie, weinig tot geen ervaring hadden met werken op afstand (zie tabel 1). Driekwart van de professionals had echter wel het gevoel dat zij over de juiste hulpmiddelen en minimaal voldoende vaardigheden beschikte of (gedurende de lockdown) is gaan beschikken. De sessie waarover de professionals rapporteerden zijn via beeldbellen en telefoon gedaan.

In de interviews werd door de professionals ook vaak gerefereerd aan het belang van technische randvoorwaarden voor hulp op afstand (goede internetverbinding, goede kwaliteit beeld en geluid). Daarnaast werd een aantal functionele voorwaarden genoemd, zoals de functies die een programma biedt (scherm delen, opnames maken, whiteboard) en de gebruiksvriendelijkheid hiervan. Het is bijvoorbeeld belangrijk dat de programma's in de beveiligde, digitale omgeving van de werkgever gebruikt kunnen worden, dat het makkelijk is anderen uit te nodigen voor een gesprek (bijvoorbeeld via een link) en dat cliënten niet van alles hoeven te installeren. Er werden ook zaken genoemd die de professional zelf kan doen om de hulpmiddelen zo effectief mogelijk te gebruiken. Zo is het belangrijk dat je, voorafgaand aan het contact met cliënten, als professional vaardig bent met het gebruikte programma, de cliënt voorbereidt op de gang van zaken, en duidelijke afspraken maakt (begin- en eindtijd, privacy en etiquette rond online contact). Het maken van duidelijke afspraken is wellicht extra belangrijk omdat pvrofessionals ook aangeven dat online afspraken als vrijblijvender worden ervaren door cliënten. "Dan had je een afspraak staan en neemt het kind op en dan zit-ie opeens in de auto. Dan kun je een heel leuk plan hebben wat je wilt doen, maar dan kan dat niet. Je hebt ook minder eigen regie over het proces."

Genoemde belangrijke afspraken over online etiquette zijn onder meer het hebben van een rustige plek om te zitten, een rustige achtergrond, de microfoon op mute als je niet spreekt en je bovenlijf en armen goed in beeld. Dit geldt voor zowel de professional als de cliënt. Tijdens het contact is het daarnaast belangrijk om zaken meer expliciet uit te spreken, uit te leggen en te checken. Bijvoorbeeld uitspreken wat je zelf doet en denkt, en checken of je wat de ander doet en denkt op de juiste manier interpreteert. "En dat je ook verduidelijkt van: joh, als ik nu wegkijk, ben ik aan het schrijuen. Dat je wat meer expliciteert van wat je aan het doen bent."

Professionals geven daarnaast aan dat het vele online werken vanuit huis tijdens corona hun energie, werkplezier en zwaarte van het werk op een negatieve manier heeft beïnvloed. En dat zij het live contact met cliënten en collega's misten. "Normaal gesproken kan je heel even bij een collega binnenlopen en zeggen: "Ik maak me zorgen, heb ik dit goed aangepakt, wat zou jij doen?" En dat valt natuurlijk ook weg als je thuis alleen achter je laptop zit. Dat maakt het werken, denk ik, ook wel wat zwaar. Dat overleg met collega's niet vanzelfsprekend is."

\section{ZORGEN OM DE PRIVACY}

De sessie waarover professionals de vragenlijst invulden zijn in de meeste gevallen (81 procent) vanuit huis gedaan. Hierbij gaven de meeste professionals aan dat ze de sessie waarover zij rapporteerden op een rustige plek konden doen (90,2 procent van de professionals), waarbij ze het gevoel hadden vrij te kunnen praten (75,6 procent) en er geen mensen konden meeluisteren (65,9 procent). De meeste professionals maakten zich bij de sessie waarover zij rapporteerden geen zorgen over de veiligheid van de verbinding ( 80 procent). In de interviews gaven professionals aan dat er wel aspecten zijn van het online contact met kinderen en ouders die de privacy mogelijk in gevaar brengen. Een van de meest genoemde zorgen is het gebruik van onveilige programma's. Professionals gaven onder

Tabel 1 Beschrijving van deelnemers aan het onderzoek.

\begin{tabular}{|l|r|}
\hline Functie & \\
\hline orthopedagoog & $34 \%$ \\
\hline psycholoog & $12 \%$ \\
\hline GZ-psycholoog & $14 \%$ \\
\hline anders & $40 \%$ \\
\hline Werkzaam in: & $27 \%$ \\
\hline jeugd-geestelijke gezondheidzorg & $9 \%$ \\
\hline jeugdzorg & $12 \%$ \\
\hline $\begin{array}{l}\text { ambulante of preventieve } \\
\text { hulpverleningssetting }\end{array}$ & $12 \%$ \\
\hline onderwijssetting & $14 \%$ \\
\hline gehandicaptenzorg & \\
\hline Aantal jaren werkervaring & 6,6 jaar \\
\hline gemiddeld & $1-33$ jaar \\
\hline range & \\
\hline $\begin{array}{l}\text { Eerdere ervaring met online } \\
\text { cliëntcontact }\end{array}$ & $61,5 \%$ \\
\hline weinig tot geen & $30,7 \%$ \\
\hline enigszins & $7,7 \%$ \\
\hline veel & \\
\hline
\end{tabular}


meer aan dat programma's die laagdrempelig en gebruiksvriendelijk zijn, zoals Whatsapp, Facetime en Zoom, niet altijd als voldoende beveiligd aangemerkt zijn en dat soms in verband met de laagdrempeligheid toch voor deze programma's wordt gekozen. Dit leverde professionals dilemma's op. "Dus toen heb ik een mail of een appje uitgestuurd naar al mijn studenten om ze voor de veiligheidsrisico's van Whatsapp te waarschuwen en te vragen of het wellicht via Teams zou kunnen en wat hun voorkeur is. En daar merk ik toch dat het merendeel toch kiest voor Whatsapp."

Hieraan gerelateerd gaf een aantal professionals aan dat er na de start van de eerste lockdown lang onduidelijkheid was over welke programma's veilig waren

\section{ONLINE MOET JE ALLES NÓG MEER BENOEMEN EN UITLEGGEN}

of dat informatie hierover inconsistent of moeilijk te vinden was. Omdat zowel professional als cliënt de gesprekken tijdens die lockdown vanuit huis voerde, was er tevens zorg over derden die met het gesprek mee kunnen luisteren. "Wat ook wel een aandachtspunt is, en dat doen mensen niet eens bewust hoor, maar dan loopt er opeens bij cliënt iemand door het beeld. Dan denk je: hè, wie is dat? Of een broer of zus en dan denk ik: o ja, even navragen, waar zit je dan?"

Gerelateerd hieraan gaven professionals aan dat online contact met cliënten vanuit huis ervoor zorgt dat werk en privé moeilijker gescheiden te houden zijn, bijvoorbeeld omdat hun woning op de achtergrond te zien is. Er werden daarnaast ook dingen genoemd die professionals helpen om hun eigen privacy en die van de cliënt te waarborgen, waaronder het gebruik van een werktelefoon en werklaptop, veilige hulpmiddelen en software, en het gebruik van een headset. Ook een plek met een rustige en neutrale achtergrond, duidelijke afspraken met huisgenoten over binnenlopen en duidelijke afspraken met cliënten kunnen de privacy bevorderen. "Ik denk wel dat we misschien nog meer alert moeten zijn. Aan de cliënt van tevoren vragen: 'Wie is er bij je, waar zit je nu en hoe is het?' Van tevoren duidelijk hebben dat je een therapiegesprek hebt en dat privacy daarbij belangrijk is. Dus privacy zelf nog meer bespreken, aan het begin van beeldbellen en dat herhalen."

\section{KWALITEIT VAN CONTACT WISSELT}

Over het contact of de therapeutische alliantie in de specifieke sessies waarover in de vragenlijst is gerapporteerd, zijn de professionals gemiddeld tevreden (zie tabel 2).

In de interviews gaven professionals aan dat ze het contact met cliënten online als erg wisselend ervaren. Bij sommige cliënten verloopt het online contact minder goed dan live contact, maar met anderen verloopt het net zo goed als live, of zelfs beter. "Ik merkte dat als je juist niet samen in een kamer zit, maar als iemand gewoon in zijn eigen omgeving is, en kan praten op een plek die voor hem of haar vertrouwd is, dat dat juist hele open gesprekken gaf, waarbij ze ook wel dingen durfden te vertellen die ze eerder in de face-to-face-gesprekken nog niet hadden verteld."

Professionals gaven aan dat contact makkelijker gaat als al sprake is van een behandelrelatie. Er werden daarnaast een aantal cliëntfactoren genoemd die mogelijk een verklaring bieden voor de verschillen in contactname online, waaronder de leeftijd van de cliënt en de vorm en zwaarte van de problematiek. Specifiek wordt genoemd dat het contact met jonge kinderen lastiger is dan met adolescenten of volwassenen. Bij kinderen is het onder meer lastiger om de aandacht vast te houden of een situatie te creëren waarin ze vrijuit kunnen praten. Bijvoorbeeld omdat ze hulp nodig hebben van gezinsleden om de techniek op te starten of omdat ze gaan rondlopen en dan in contact komen met andere leden van het gezin. "Het contact met kleine kinderen was wel heel lastig. Die kunnen niet zo lang stil zitten, achter een schermpje. Dat zijn normaal gesproken ook geen praattherapieën. Je doet heel veel, samen bladen invullen. Ze kunnen eigenlijk niet goed genoeg schrijven om dat zelf in te vullen."

Bij adolescenten lijkt dit makkelijker, maar ook hier werd genoemd dat de aandacht moeilijk vast te houden is en dat adolescenten beeldbellen (met zichzelf in beeld) soms confronterend vinden. Daarnaast gaven professionals aan dat angst, stemmings- en persoonlijkheidsproblematiek kunnen bijdragen aan moeizaam online contact, bijvoorbeeld omdat deze cliënten liever niet beeldbellen, zich afsluiten en contact vermijden. Dit laatste wordt ook als algemeen punt genoemd, dat

Tabel 2 Rapportcijfer (0-10) dat professionals geven aan inhoud en contactname in de specifieke sessie waarover zij rapporteerden.

\begin{tabular}{|l|c|c|c|}
\hline Op een schaal van 1 tot 10, hoe tevreden bent u over: & $\begin{array}{c}\text { Minimale } \\
\text { score }\end{array}$ & $\begin{array}{c}\text { Maximale } \\
\text { score }\end{array}$ & Gemiddelde \\
\hline Het contact of de therapeutische alliantie & 3 & 8 & 7 \\
\hline De doelen en onderwerpen & 1 & 10 & 7 \\
\hline De aanpak en werkwijze & 1 & 10 & 6 \\
\hline Het algehele gesprek & 0 & 9 & 6 \\
\hline
\end{tabular}


kunnen opnemen met therapeut, of hun eigen verhaal kunnen opschrijven. Er zijn ook een aantal dingen die volgens professionals niet of minder goed mogelijk zijn op afstand, zoals diagnostiek, observatie, sommige vormen van exposure, modeling en oefenen (specifiek dingen waarbij fysiek contact is, zoals psychomotore therapie). "Maar wat wij ook veel doen is non-verbale vormen van therapie. Als je dat nu wil opstarten, PMT maar ook Shereborn samenspel, of ritmische massage, dat is wel veel meer zoeken en dat kan gewoon niet via beeldbellen."

\section{MET DE HOND OP SCHOOT}

In de vragenlijst gaf een groot deel van de professionals aan dat hulpverlening op afstand volgens hen over het algemeen minder effectief is (67,5 procent). De overige professionals waren van mening dat het niet minder en niet meer effectief is. In de interviews schetsten professionals ook een wisselend beeld van de effectiviteit van hulp op afstand. In sommige gevallen kwamen professionals überhaupt niet tot behandelen, omdat cliënten door de pandemie bijvoorbeeld andere dingen aan hun hoofd hadden, of doordat de geplande behandelmethode digitaal niet door kon gaan. In andere gevallen sloot eventueel vervangende of aangepaste hulp op afstand minder goed aan bij de soort of zwaarte van de problematiek of de kenmerken van de cliënt, bijvoorbeeld zijn leeftijd of licht verstandelijke beperking. Ook werd genoemd dat het contact met cliënten vaak korter was en minder diepgang had, onder meer doordat professionals veel tijd kwijt waren aan het creëren van de (technische) randvoorwaarden voor behandeling, doordat cliënten minder vrijuit konden praten, sneller afgeleid waren of de afspraak minder als echte behandelafspraak zagen. "Ineens zitten mensen met de hond op schoot, of er wordt aangebeld. Het is die ruis erombeen die je toch uit het proces haalt en maakt dat je niet altijd even goed aan de therapierandvoorwaarden kunt voldoen. Die moet je echt meer blijven bewaken."

Sommige van deze factoren relateerden professionals aan de pandemie of zijn er zelfs onlosmakelijk mee verbonden. Gezinnen zaten thuis, kinderen gingen niet naar school, ouders moesten werk en opvoeding combineren en er waren zorgen over gezondheid en inkomen. Hieraan gerelateerd merkten sommige professionals bij cliënten nieuwe of een intensivering van klachten. Daardoor hadden professionals soms het idee dat ze tijdens cliëntcontact vooral bezig waren met de COVID-uitbraak, in plaats van met de oorspronkelijke hulp- of behandeldoelen. "Voor sommige kinderen was school een bron van steun, en nam de stress tijdens de lockdown erg toe, verergerden de klachten. Dan ben je dus inderdaad vooral bezig met stabiliseren in de behandeling."

Echter, voor andere cliënten bracht de pandemie juist verlichting in klachten of meer rust om aan hulp- of behandeldoelen te werken. Dit bleek bevorderend voor de effectiviteit van de behandeling. "Dus dat je een klacht in remissie ziet en dat er daardoor vaak ook weer meer ruimte komt om gericht aan die trauma's te werken bijvoorbeeld."

Ook het feit dat de behandeling in de thuissituatie plaatsvond droeg voor sommige cliënten bij aan de effectiviteit. "Mijn indruk is dat ouderbegeleiding makkelijker is met beeldbellen. Dat ouderbegeleiding die ik geef heel constructief kan zijn. Meer to the point. Doordat er mogelijk meer afstand is, durf $i k$ ook de vinger op de zere plek te leggen.” (...) "Soms hebben ze de kat of hond op schoot en dan voelen ze zich wat vrijer. Ze hoeven de deur niet uit, ze voelen zich minder bekeken. Dat was een onverwacht voordeel."

Figuur 1 Overzicht van hulpvragen in de specifieke sessies waarover professionals rapporteerden.

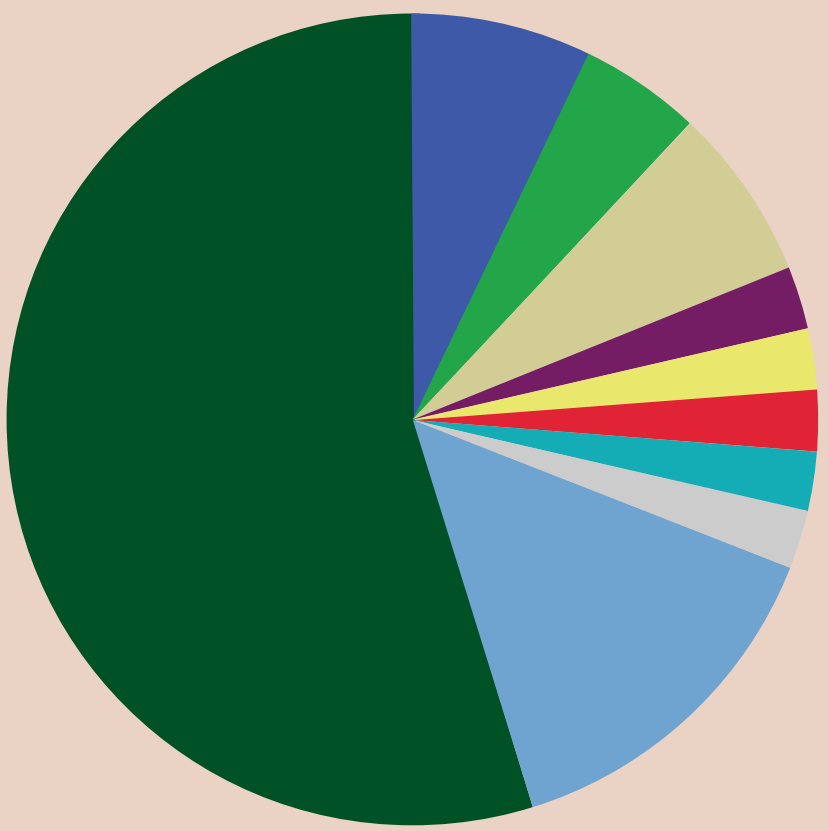

\section{Hulpvraag}

- Verwerking van ingrijpende gebeurtenissen (trauma)

- Angstklachten van het kind Gedragsproblemen van het kind

- Ontwikkelingsproblemen van het kind Rouwverwerking of echtscheiding

- Problemen in de ouder-kindrelatie/hechting sproblemen

- Opvoedingsproblemen

Overige sociaal-emotionele en psychosociale problemen van het kind

- Anders

- Meerdere hulpvragen 


\section{Box 1: Taken}

Er liggen op alle betrokkenen nog een aantal taken te wachten om hulp op afstand in de toekomst nog beter te kunnen vitvoeren.

Voor werkgevers

- Hardware in orde maken (devices die geschikt zïn voor beeldbellen en thuiswerken, goede internetverbinding).

- Geschikte software beschikbaar stellen (gebruiksvriendelijke en veilige tools en programma's).

- Duidelijke protocollen en richtlijnen voor jeugdhulp op afstand ontwikkelen (o.a. privacy).

Voor ontwikkelaars

- Tools ontwikkelen voor online risicotaxatie en diagnostiek.

- Vertaling van minder talige methoden, zoals speltherapie en observatie, naar online varianten.

Voor professionals

- Eigen maken van online tools.

- Kennis en kunde over online contact opbouwen en onderhouden.

- Zoeken naar manieren om energie, balans, contact met collega's te behouden.

Voor onderzoekers

- Onderzoek naar de effectiviteit van online jeugdhulp.

- Onderzoek naar individuele verschillen in effectiviteit van online jeugdhulp.

\section{Box 2: Meer informatie en praktische tips}

NIP: https://covid.psynip.nl/actueel/themas/thema/coronavirus/ NVO: https://covid.nvo.nl/nvo-in-t-kort/themadossiers/corona-virus. aspx

NJi: https://covid.nji.nl/coronavirus\#rowlndex7

KJP: https://covid.kenniscentrum-kjp.nl/professionals/dossiers/

kinder-jeugdpsychiatrie-corona/

Gehandicaptenzorg: https://covid.kennispleingehandicaptensector.nl/ coronavirus/omgaan-met-mentale-effecten-coronacrisis-zorgprofessional

Daarnaast ervoeren verschillende professionals dat kinderen en gezinnen tot meer in staat waren dan zij hadden verwacht. "En misschien ook wel dat de veerkracht van leerlingen er echt uit blijkt. Die onderschatten we misschien soms, wat ze wel en niet kunnen en dat je toch iets meer ziet dat ze er best wel goed toe in staat zijn."

\section{BEELDBELLEN ZO GEK NOG NIET}

In de interviews noemden professionals verschillende dingen die ze voor de toekomst willen behouden. Het gebruik van beeldbellen werd vaak genoemd en, deels hieraan gerelateerd, de flexibiliteit en de efficiëntie die online werken henzelf en de cliënten geeft. Zo gaven professionals aan dat beeldbellen met cliënten die ver weg wonen of die lastig in te plannen zijn meer ruimte geeft. Maar bijvoorbeeld ook dat een gesprek met meerdere partijen, zoals een multidisciplinair overleg, makkelijker in te plannen is online. Ook gaven een aantal professionals aan dat online werken, en dan specifiek ook (deels) thuiswerken, hen ook veel voordelen oplevert, zoals besparing van reistijd en het zich beter kunnen concentreren op verslaglegging. "Ik schat in dat er bij meer gezinnen een soort combinatie zal plaatsvinden. En dat kan dus zijn dat je alleen, bijvoorbeeld, vader ziet en moeder op afstand, of dat je sommige sessies live en sommige op afstand doet. Dat levert veel op qua reistijd en agenda, voor beide partijen."

Hieraan gerelateerd werd echter ook aangegeven dat het belangrijk is om aandacht te besteden aan het bewaken van de eigen grenzen en energie. "Aan de ene kant zie ik dat mensen flexibeler zijn met avonduren en dat soort dingen. Dat het veel biedt. Maar ik denk dat het ook zoeken is naar een nieuw evenwicht."

Daarnaast gaven een aantal professionals aan dat ze willen doorgaan met het tussendoor hebben van (extra) contactmomenten via online middelen, zoals e-mail, bellen, beeldbellen en online modules. "I $k$ denk wel dat ik even vaak tussendoor ga bellen [als tijdens de lockdown]. We hebben niet echt een hele afspraaktrouwe doelgroep en soms waren ze te laat. Dan ging ik de afspraak meestal gewoon verzetten naar een volgende week ofzo, maar nu denk ik: ik kan ook wel even meteen beeldbellen."

Professionals gaven ook aan dat er nog dingen nodig zijn om voor langere tijd op afstand met cliënten te kunnen werken. De meest genoemde zijn hardware en

\section{HULP OP AFSTAND VERLAAGT DREMPEL VOOR SOMMIGE CLIËNTEN}

fysieke werkomgeving, tools en manieren om het contact met cliënten op te bouwen en te onderhouden. En dat zij zelf nog meer zouden willen leren en wellicht meer ervaring moeten opdoen met online methoden en technieken. Specifiek zouden zij meer handvatten willen om het contact met nieuwe cliënten online op te bouwen en met bestaande cliënten te behouden. "Wat wil ik nog leren? Die werkrelatie opbouwen of herstellen op het moment dat je merkt dat iemand zich terugtrekt. En iemand is heel snel weg op beeld, emotioneel gezien is die afstand er heel snel. En ja, daar zijn vast technieken voor. I $k$ weet dat er mensen zijn die dit al heel lang doen en zo werken en ook met succes."

Zaken die volgens hen nog ontwikkeld moeten worden, zijn onder meer tools voor diagnostisch onderzoek en risicotaxaties op afstand. Ook werd meerdere keren genoemd dat er aandacht moet zijn voor het afstemmen met derden, het doorverwijzen (wat nu soms stil lag), en onderzoek naar de effectiviteit van online hulpverlening. 


\section{TOT SLOT}

In de jeugdhulpverlening zijn we veelal niet gewend om op afstand te werken. De abrupte en gedwongen transitie van live naar online contact vergde mede daarom enorm veel flexibiliteit en creativiteit van professionals. Desondanks schetsen professionals een genuanceerd beeld van hun ervaringen met werken op afstand (specifiek beeldbellen) en gaven zij ook aan sommige aspecten van hulp op afstand voor de toekomst te willen behouden (onder andere de efficiëntie van online werken en de flexibiliteit voor cliënten). Professionals noemden daarnaast verschillende punten die nog aandacht behoeven wanneer nieuwe maatregelen live contact opnieuw belemmeren. $\mathrm{Zij}$ zien hierin belangrijke taken voor werkgevers, ontwikkelaars, onderzoekers en zichzelf (zie box 1). De afgelopen tijd is op meerdere plekken belangrijke informatie hiervoor verzameld en gedeeld (zie box 2).

Een belangrijk punt van aandacht is dat we nog weinig weten over de effectiviteit van werken op afstand, specifiek op de lange termijn. Eerder onderzoek laat zien dat specifieke methoden of technieken mogelijk even effectief zijn op afstand vergeleken met een face-to-face toepassing, bijvoorbeeld de effectiviteit van online cognitieve gedragstherapie voor het behandelen van angst en depressie bij adolescenten (zie voor een overzicht Grist e.a., 2019) en online opvoedprogramma's voor het verbeteren van opvoedgedrag en verminderen van gedragsproblemen (zie voor een

\section{LITERATUUR}

> Aafjes-van Doorn, K., Békés, V., \& Prout, T.A. (2020). Grappling with our therapeutic relationship and professional self-doubt during COVID-19: will we use video therapy again? Counselling Psychology Quarterly, 1-12.

> Békés, V., \& Aafjes-van Doorn, K. (2020). Psychotherapists' attitudes toward online therapy during the COVID-19 pandemic. Journal of Psychotherapy Integration, 30(2), 238.

$>$ Berger, T. (2017). The therapeutic alliance in internet interventions: A narrative review and suggestions for future research. Psychotherapy Research, 27(5), $511-524$.

> Connolly, S.L., Miller, C.J., Lindsay, J.A., \& Baver, M. S. (2020). A systematic review of providers' attitudes toward telemental health via videoconferencing. Clinical Psychology: Science and Practice, 27(2), el2311.

> Farmer, R.L., McGill, R.J., Dombrowski, S.C., McClain, M.B., Harris, B., Lockwood, A.B., ... \& Benson, N.F. (2020). Teleassessment with children and adolescents during the coronavirus (COVID-19) pandemic and beyond: Practice and policy implications. Professional Psychology: Research and Practice, $51(5), 477-487$.

$>$ Florean, I.S., Dobrean, A., Pâsârelu, C.R., Georgescu, R.D., \& Milea, I. (2020). The efficacy of internet-based parenting programs for children and adolescents with behavior problems: A meta-analysis overzicht Florean e.a., 2020) lijkt vergelijkbaar met hun live variant. Maar over de effectiviteit van andere online methoden is veel onbekend. Ook geven professionals in ons onderzoek aan dat de geschiktheid van hulp op afstand wellicht sterk verschilt tussen cliënten. Onderwerpen waar we ook weinig over weten zijn de validiteit van het online toepassen van gestandaardiseerde testdiagnostiek (Farmer e.a., 2020) en de kwaliteit van het therapeutisch contact zoals cliënten die ervaren. Ons onderzoek en eerdere onderzoeken laten grote individuele verschillen zien in hoe professionals de kwaliteit van online contact ervaren, waarbij zij als dat tot de mogelijkheden behoort - een voorkeur hebben voor live of hybride ('blended') contact (Berger, 2017; Norwood e.a., 2018; Owen, 2020).

Uitgebreider en langetermijnonderzoek naar factoren die bijdragen aan de effectiviteit van online jeugdhulp is nodig, ook na de coronacrisis. Aan de hand daarvan kan de effectiviteit bepaald worden zonder de extra stresserende factor (zoals zorgen om gezondheid, thuiswerken, het combineren van zorgtaken en werk) van de pandemie. De eerste bevindingen benadrukken dat, ongeacht de situatie, hulp op maat (Kamp e.a., 2020) en algemene therapeutvaardigheden (sensitiviteit, online communicatievaardigheden) (Simpson \& Reid, 2014) belangrijke pijlers van de jeugdhulp zijn. En dat in tijden waarin we onze werkwijzen moeten aanpassen aan wat mogelijk is, deze pijlers mogelijk extra belangrijk worden. of randomized clinical trials. Clinical Child and Family Psychology Review, 23(4), 510-528.

> Grist, R., Croker, A., Denne, M., \& Stallard, P. (2019). technology delivered interventions for depression and anxiety in children and adolescents: A systematic review and meta-analysis. Clinical Child and Family Psychology Review 22(2), 147-171.

$>$ Kamp, D., Machielsen, G., \& van Os, J. (2020). Voorpublicatie: De toepassing van psychotherapeutische behandeling via beeldbellen. Tijdschrift Voor Psychotherapie, 3. https://covid.tijdschriffvoorpsychotherapie.nl/archief/jaargang-2020-uitgave-3/1 1676/

$>$ MacEvilly, D., \& Brosnan, G. (2020). Adapting an emotional regulation and social communication skills group programme to teletherapy, in response to the COVID-19 pandemic. Irish Journal of Psychological Medicine, 11, 1-6.

> Racine, N., Hartwick, C., Collin-Vézina, D., \& Madigan, S. (2020). Telemental health for child trauma treatment during and post-COVID-19: Limitations and considerations. Child Abuse \& Neglect, 110, 104698.

$>$ Schieltz, K.M., \& Wacker, D.P. (2020). Functional assessment and function-based treatment delivered via telehealth: A brief summary. Journal of Applied Behavior Analysis, 53(3), 1242-1258.

> Simpson, S.G., \& Reid, C.L. (2014). Therapeutic alliance in videoconferencing psychotherapy: A review. Australian Journal of Rural Health, 22(6), 280-299. 